\title{
Kinesiology in the 4th Industrial Revolution and Pandemic Era
}

\author{
Kijin $\mathrm{Kim}^{*}$ \\ President of Korean Academy of Kinesiology; \\ Department of Physical Education, College of Physical Education, Keimyung University, Republic of Korea
}

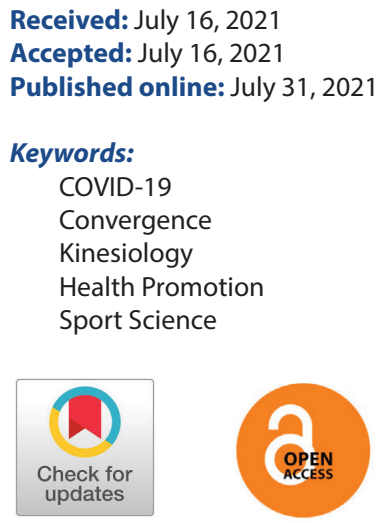

*Correspondence: Kijin Kim, Department of Physical Education, College of Physical Education, Keimyung University, 1095 Dalgubeuldero, Dalseo-gu, Daegu, Korea; Tel: +82-053-580-5256; Fax: +82-053-580-5314; E-mail: kjk744@kmu.ac.kr
The 4th industrial revolution and the pandemic caused by COVID-19 have required tremendous changes and innovations in sport science and Kinesiology. Identifying and preparing for these changes will be an important part for the development of Kinesiology. The large flow of change can be viewed by dividing it into the areas of exercise performance improvement and health promotion. In addition, in the convergence field, as a new untact industry field, sports convergence industries such as online-related industries, virtual reality, sports and immersive content technology are being tried. There is a new demand for a platform for improving the performance of elite sports using the un-tact industry, active convergence in the sports industry, and multi-sports with an omni-channel system that combines virtual reality and artificial intelligence [1,2]. Fundamentally, in the field of Kinesiology, innovation is required to construct a new academic paradigm centered on convergence with various disciplines.

Significant lack of exercise, along with depression and other mental health-related diseases, is being emphasized as the most serious health risk factor since the pandemic [3]. The higher the physical activity and the better the cardiopulmonary function, the lower the possibility of infection with COVID-19 and the lower the mortality rate [4]. Therefore, the importance of regular physical activity and exercise programs for improving physical fitness based on sport science and Kinesiology is being emphasized. In addition to the evidence-based systematization and diversification for health promotion, a wide range of convergence and complex processes including field grafting should be carried out. As a detailed example, the digital health care system is a high-tech convergence system using advanced technologies such as artificial intelligence, big data, robot industry, internet of things, 3D printing, virtual augmented reality, stem cell, and gene rehabilitation treatment techniques of genome analysis and the like [5].

Looking at detailed approaches to improving the performance of athletes that have emerged after the pandemic, training guidelines, home work-out Program for training for each body part, on-offline psychological tests, measures to strengthen the social responsibility of sports, and video program include analysis and utilization plans, talk 
concerts for revitalizing sport science, nutritional analysis programs for individual players, development of training programs to improve physical fitness during winter season, and guidelines for return to play in the field of injury prevention and rehabilitation [5].

What will the new Kinesiology that require the 4 th industrial revolution and pandemic look like? What should be prepared to meet that need? The three most important factors can be highlighted: First, above all else, it must be faithful to the academic segmentation and identity of Kinesiology. Second, it is necessary to promote convergence with various disciplines. Third, it must be developed into a science that is human-centered and capable of performing practical roles for humans at the same time. It is important for AJK to develop into a field that can contribute to the convergence of various disciplines along with papers that study the specific field of Kinesiology in depth.

\section{References}

1. Shepherd J, Carter L, Pepping G, Potter L. Towards an operational framework for designing training based sports virtual reality performance simulators. Inter-Society Electronic Arts 2018; 2(6):1-7.

2. Kim Y, Moon YE. An empirical research on psychological resistance factors of omni channel's unmanned order payment system. J Internet Electro Com Res. 2018; 18(6):1-19.

3. Giuntella O, Hyde K, Saccardo S, Sadoff S. Lifestyle and mental health disruptions during COVID-19. Proc Natl Acad Sci USA, 2021; 118(9):e2016632118. doi: 10.1073/ pnas.2016632118.

4. Cho D, Lee SJ, Jae SY, Kim WJ, Ha SJ, Gwon JG, Choi J, Kim DW, Kim JY. Physical activity and the risk of COVID-19 infection and mortality: a nationwide population-based case-control study. J Clin Med. 2021; 10(7):1539. doi: $10.3390 / \mathrm{jcm} 10071539$.

5. Kim K. Future-oriented development plan of sports science for changes required after COVID-19. J Coaching Develop. 2021; 23(2):290-295. 